Article

\title{
Evaluation of Sustainable Regional Development Combining Remote Sensing Data and Ecological Constraints: A Case Study of Chaohu Basin, China
}

\author{
Beibei Guo ${ }^{1, *(\mathbb{C},}$, Xiaobin Jin $2,3,4 \oplus$, Yelin Fang ${ }^{1}$ and Yinkang Zhou ${ }^{2,3,4}$ \\ 1 School of Business, Anhui University, Hefei 230601, China; fangyelin2006@126.com \\ 2 School of Geography and Ocean Science, Nanjing University, Nanjing 210093, China; jinxb@nju.edu.cn (X.J.); \\ drzhyk@nju.edu.cn (Y.Z.) \\ 3 The Key Laboratory of the Coastal Zone Exploitation and Protection, Ministry of Land and Resource, \\ Nanjing 210023, China \\ 4 Natural Resources Research Center, Nanjing University, Nanjing 210093, China \\ * Correspondence: guobbyuanks@126.com
}

Received: 21 October 2020; Accepted: 23 November 2020; Published: 25 November 2020

\begin{abstract}
The maintenance of sustainable development in light of climate change is presenting society with a serious challenge. This study analyzes the spatial environment and its coupled relationship with socio-economic and food security in the Chaohu Lake Basin in central Anhui Province, China. Previous studies have shown that this study area has good environmental conditions. However, the ecological security, economic development, and food security in the Chaohu Lake Basin was generally poor and poorly coordinated in 2018, especially in the center of local cities and surrounding areas. Nevertheless, many towns are in a well-organized state, meaning sustainable and coordinated regional development can be achieved through resource optimization. Generally, the economic conditions in the Chaohu Lake Basin should be improved in a way that ensures that the environment is not significantly degraded. The main functional zoning requirements of the counties' land management planning designate most of the counties as parts of ecological conservation areas. The present study provides monitoring of important basin ecosystems and serves as a guide to future sustainable regional development by providing directions and paths to follow; it can also provide a reference for eco-functional zoning that is applicable to various natural basins worldwide.
\end{abstract}

Keywords: environmental quality; sustainable development; eco-social-economic system; coupling; Chaohu Lake Basin; China

\section{Introduction}

Global environmental change and sustainable regional development are topics of increasing relevance as human modification of the global landscape continues unabated. As stated in the 2019 United Nations Global Sustainable Development Report, the terrestrial ecosystem of China still faces significant challenges. Implementing sustainable land-use practices requires integrating agricultural and climatic interventions. Current land use patterns are not meeting people's needs while agriculture destroys forests and biodiversity, squanders water, and releases one-quarter of global greenhouse-gas emissions. Since the late 1980s, the economy of China has been developing rapidly [1], while at the same time economic development has also caused damage to the environment. The environment of China is fragile in many regions, and the trend of environmental deterioration has not been effectively addressed in recent years. In 1999, pilot projects for the "Grain for Green" program were implemented in some regions of China, and the program was introduced nationwide [2] starting in 20 January 2003. So far, more than 33.80 million $\mathrm{hm}^{2}$ of farmland has been returned to forests or grasslands. Because 
the area of cultivated land has gradually decreased in recent years, food security is also an important topic. Economic development always conflicts with the development of sustainable agricultural production and an ecologically sound civilization to a certain extent; knowing how to coordinate the relationships in an "ecological-economic society" can provide a powerful way to promote sustainable regional development.

After China's reform and opening up processes, with the rapid increase in population and land [3-5] urbanization of China, a larger proportion of the rural populations migrated to urban areas for various reasons [6-8]. The effects of this change in population on ecosystem function have been considered in the analysis of the effects of sustainable development of human-natural systems. Attention needs to be paid to minimizing negative ecological impacts and protecting the visual quality of the environment $[9,10]$. The rational allocation of resources including water, land, and human resources integrates the social and ecological impact of these changes and is involved in the initiative to modernize the economy [11,12]. Rapid economic development is a double-edged sword for environmental security $[13,14]$ because improving the environment requires investment [15] while economic development negatively affects ecological resources [16]. Increasing agricultural production involves the almost irreconcilable problem of supporting economic growth while conserving the environment and working toward the goal of sustainable development $[17,18]$. Changes in polices and administrative jurisdictions [19] can promote local economic development indirectly affect the environment. While developing its economy in recent years, China has also attached great importance to protecting the environment as one of the countries worldwide that has initiated policies that support ecological compensation. The principle of ecological compensation is based upon the concept of "those who develop are those who protect; those who destroy are those who restore; those who benefit are those who compensate; those who pollute are those who pay for pollution." Promoting local economic development will indirectly affect the environment. While developing its economy in recent years, China has also attached great importance to the protection of the environment, making it of the main countries worldwide that initiated ecological compensation. The principle of ecological compensation is based upon the idea that "who develops, who protects; who destroys, who restores; who benefits, who compensates; who pollutes, who pays" [20]. At the current stage of development, China has begun to implement a plan for the rehabilitation of cultivated land, grasslands, rivers, and lakes and has conducted pilot projects in some regions and watersheds. However, the system designed to support and protect cultivated land has lagged behind, which seriously affects the advancement of cultivated land protection. It is important to coordinate the relationship between the socio-economic (SE) development of the basin and the development and use of resources, and to manage the relationships involved in resource use between regions and departments.

Under the Sustainable Development Goals (SDGs) of the United Nations, conducting a multi-dimensional sustainability assessment is necessary during regional development. Many scholars use the coupling function to study the relationship between the SDGs, while the direction of sustainable development involves more than two subsystems [21-23]. Complexities in sustainability evaluations of subsystems will reflect multiple roles and these roles need to be integrated [24-26]. It is interconnected and holistic, and previous studies lack systematic and comprehensive holistic consideration. Scholars have explored ways of linking the SDGs, the degree of interaction [27], and the network of relationships [28]. System dynamics and evaluation methods have been used in these integration frameworks. Fu [29] connects geography and SDGs, presented a classification-coordination-collaboration approach for advancing the SDGs, and found that the quantitative output results of different research scales vary greatly. Also, remote sensing technology can be used during regional sustainability assessment and monitoring [30]. In this entire process, however, it is difficult to feedback the spatiotemporal changes of sustainable development simultaneously with these methods. A remote sensing ecological index (RSEI) can be applied to environmental monitoring in urban (impervious surface) [31,32], basin [33], and agricultural engineering areas [34]. It is necessary to explore the connections between subsystems, as well as to show their spatial differences. 
Hefei, the central city of the Chaohu Lake Basin, has grown into a new first-tier city; most counties in the basin have been included in the Yangtze River Delta urban agglomeration and have experienced rapid economic development in recent years. Chaohu Lake is the fifth largest freshwater lake in China. In 2001, the administrative division of Chaohu City was revoked; the administrative divisions had been adjusted from county to city status in 1999. The entire water area was placed under the unified jurisdiction of Hefei City after 2001, and the area around the Chaohu Lake Basin experienced rapid urbanization [35].

The Chaohu Lake Basin had been a typical important grain producing area for the last several centuries. It is an important freshwater lake basin and is part of the New Yangtze River Delta urban agglomeration [36]. Studying the relationship between changes in the natural environment of the basin and the SE situation can help in monitoring important basin ecosystems and serve to provide direction and a path for future sustainable regional development. Managers of the Chaohu Lake Basin are implementing spatial ecological planning in the entire basin. Therefore, this area is a typical research object and the present study can also be used as a reference for eco-functional zoning that is applicable to various natural basins worldwide. This study constructs an eco-socio-economic sustainable development system coordination model, make an empirical study with the statistical data of Chaohu Basin, find the development status of regional subsystems, and study the relationships between subsystems. The aims of this research are based on developing an understanding of the status quo and relationships, to make the subsystems be optimized, and even promote regional sustainable development.

\section{Data Sources}

\subsection{Study Area}

The Chaohu Lake Basin is located in Jianghuai Hills of central Anhui Province, between the Huaihe and Yangtze rivers and is a typical traditional agricultural planting area. It ranges between $30^{\circ} 58^{\prime} 00^{\prime \prime}-32^{\circ} 58^{\prime} 00^{\prime \prime} \mathrm{N}$ and $116^{\circ} 24^{\prime} 30^{\prime \prime}-118^{\circ} 30^{\prime} 00^{\prime \prime} \mathrm{E}$ and covers an area of $14,203 \mathrm{~km}^{2}$ (including the $770 \mathrm{~km}^{2}$ of Chaohu Lake) [34], adjacent to the Yangtze River in the southeast, the Dabie Mountains in the west, the Jianghuai watershed in the north, and the Chuhe River valley in the northeast. Considering the availability of the data, the counties involved in the Chaohu Lake Basin were included in the study area (Yuexi County only contains one town, Yaohe town), covering five cities (Hefei, Lu'an, Anqing, Wuhu, and Ma'anshan), 19 counties and districts, and 161 towns and streets, with 33 rivers in the entire basin (Figure 1). Chaohu Lake Basin was the first national tourism and leisure zone approved by the National Tourism Administration, and also one of the first pilot demonstration areas for the development of an ecological civilization in China in which construction is prohibited within $1 \mathrm{~km}$ of a red line around the Lake; this Basin supports a population of about 10.75 million people.
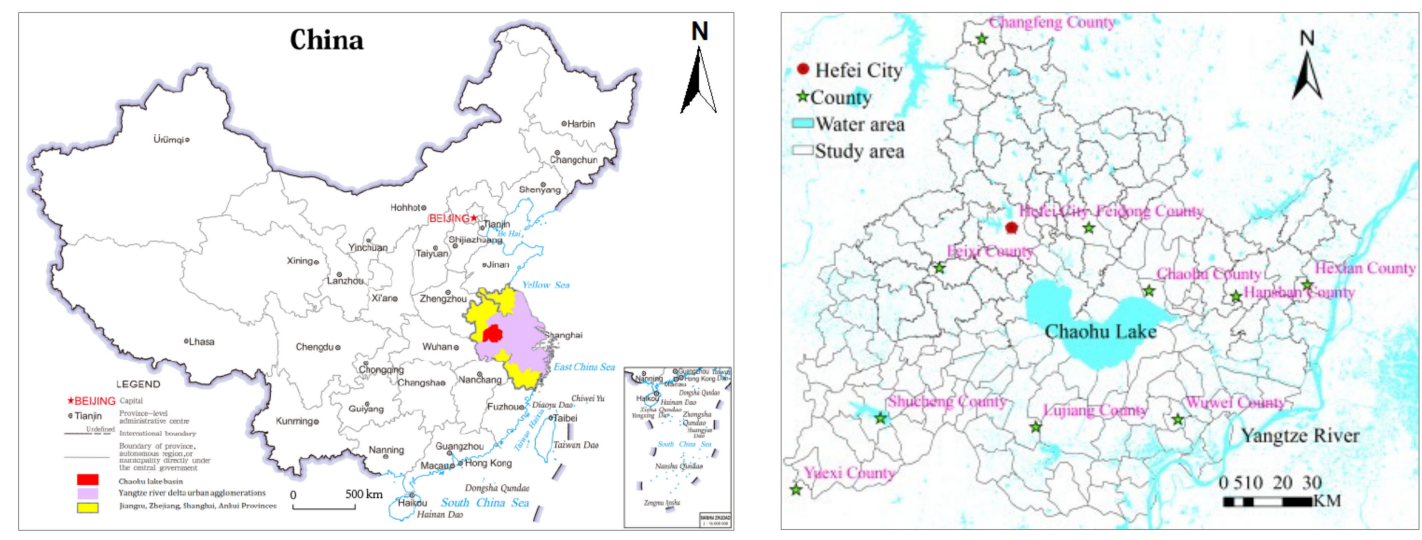

Figure 1. Location of the study area within China. 


\subsection{Data Sources}

The present study employed a long time series of high resolution $(30 \mathrm{~m})$ Landsat images. As inputs into the spatiotemporal fusion models, Landsat 8 Operational Land Imager images based on the least amount of cloud cover (less than 8.92\%) were used. Nine Landsat images (Path 120-121/Row 38) acquired in 2018 were downloaded from the US Geological Survey website (https://earthexplorer. usgs.gov); information related to the specific images is shown in Table 1. Because the downloaded Landsat data were level 1T, the data have been geometrically corrected. Using ENVI 5.3 software, first, radiant calibration of each phase of each image was conducted, so the DN value of each image was converted into the reflectivity of the sensor; next, the Fast Line-of-sight Atmospheric Analysis of Spectral Hypercubes (FLAASH) atmospheric correction tool was used to perform atmospheric correction on the visible and infrared bands of each phase to eliminate the effects of the atmosphere and the influence of factors such as reflections from some objects; then, the two images were merged by using the seamless mosaic and cubic convolution resampling method, while the annual mean values for each township were calculated using principal component analysis. Finally, ArcGIS 10.2 software was used to crop all of the data based on the boundary of the study area. The SE data was acquired from statistical yearbooks (http://tj.ah.gov.cn/) and government websites (http://www.ah.gov.cn/).

Table 1. Basic information related to Landsat Operational Land Imager imagery.

\begin{tabular}{|c|c|c|c|c|c|c|c|c|c|}
\hline Path/Row & Acquisition Date & $\begin{array}{c}\text { Center } \\
\text { Longitude }\end{array}$ & $\begin{array}{c}\text { Central } \\
\text { Latitude }\end{array}$ & $\begin{array}{l}\text { Average } \\
\text { Cloud } \\
\text { Cover }\end{array}$ & Path/Row & Acquisition Date & $\begin{array}{c}\text { Center } \\
\text { Longitude }\end{array}$ & $\begin{array}{c}\text { Central } \\
\text { Latitude }\end{array}$ & $\begin{array}{c}\text { Average } \\
\text { Cloud } \\
\text { Cover }\end{array}$ \\
\hline \multirow{5}{*}{$121 / 38$} & 5 February 2018 & 117.309 & 31.742 & 0.74 & \multirow{5}{*}{$120 / 38$} & 3 April 2018 & 118.838 & 31.742 & 0.67 \\
\hline & 10 April 2018 & 117.286 & 31.749 & 0.03 & & 19 April 2018 & 118.834 & 31.724 & 0.31 \\
\hline & 10 July 2018 & 117.323 & 31.731 & 8.92 & & 6 June 2018 & 118.374 & 31.832 & 4.80 \\
\hline & 3 October 2018 & 117.307 & 31.731 & 6.08 & & 28 October 2018 & 118.341 & 31.832 & 0.06 \\
\hline & 20 November 2018 & 117.294 & 31.731 & 0.18 & & & & & \\
\hline
\end{tabular}

\section{Methods}

\subsection{Indicators System}

\subsubsection{The Eco-Economic-Social Sustainable Development System}

The essence of human society is a complex ecosystem formed by human economic production or the activities of daily life, social development, and changes, resource development and use, and changes in the natural environment. The composition of the composite ecosystem has three main aspects: social, economic, and natural. The system can comprehensively reflect the status of regional development, population status, environmental status and changes, and resource status; it can reflect comprehensive development in a certain area and the impact of the status quo on the composite regional environment. The status of regional economic development, social development, resource status and use, and environmental conditions directly affect the regional economic, social, resource, and environmental systems. By analyzing the complex regional environment and integrated ecosystems, the concept of an Integrated Ecosystem can be employed for interpretation. The three-dimensional development of the environment, $\mathrm{SE}$, and agricultural production need to be integrated and coordinated to achieve sustainable regional goals and requirements. The ecological subsystem helps to maintain regional ecological safety, the SE system mainly creates economic benefits to provide funding for regional development, and the agricultural production system helps to guarantee human food security (FS). The relationship between them is shown in Figure 2. 


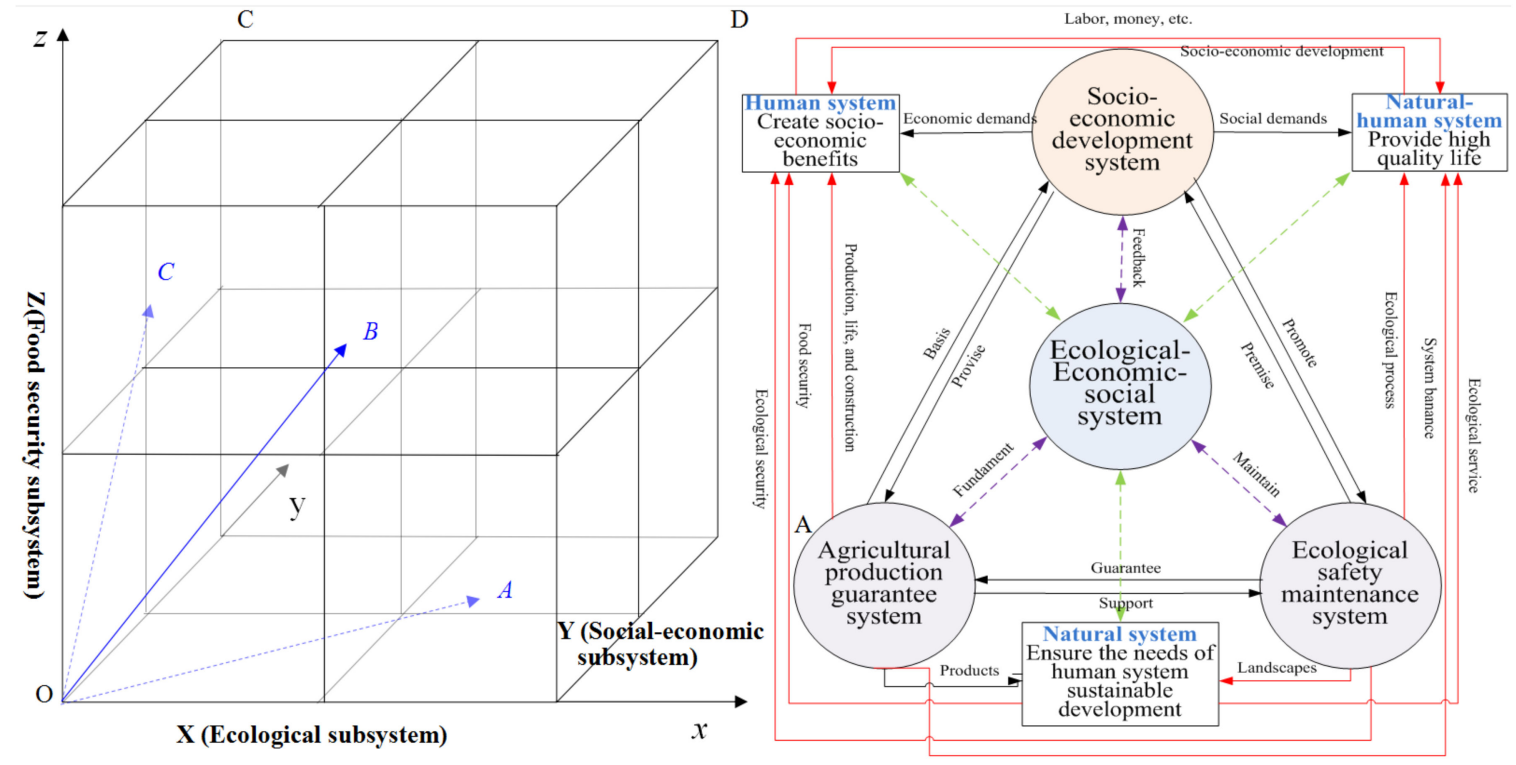

Figure 2. Structure and function of the eco-socio-economic sustainable development system. The analysis framework shows that the interconnected and holistic subsystems have connections and interactions. The purple dashed lines subcategorize the structure of the eco-socio-economic sustainable development system; the green dashed lines indicate the dominant functions and sustainable development targets of various types of sub-systems in the regional development; the black solid lines indicate the interactions among the sub-systems; the red solid lines represent the interaction mechanism within the eco-socio-economic sustainable development systems.

\subsubsection{Remote Sensing Ecological Index}

A comprehensive index is more representative than a single index. The response of environment factors in the Chaohu Lake Basin can be specifically reflected by indicators such as humidity $\left(x_{1}\right)$, greenness $\left(x_{2}\right)$, heat $\left(x_{3}\right)$, and dryness $\left(x_{4}\right)$. Among them, the distribution of soil moisture and water resources causes changes in humidity. Vegetation types, soil fertility, and water quality, which are closely related to plant growth, cause changes in greenness. Soil temperature, surface cover, and other causes changes in heat; changes in dryness are caused by soil texture, soil temperature, land degradation, or off-farm construction activities. In the technical implementation of a comprehensive index, the enhancement of thematic information with technology can be used to extract the representation information of relevant indicators from remote sensing images, such as the humidity component of heat transformation, a vegetation index, and land surface temperature (LST) representing humidity, greenness, and heat, respectively. Because buildings are an important part of the human ecosystem, the impermeable surfaces of buildings and infrastructure replace the original natural ecosystem, leading to a "drying" of the earth's surface. Therefore, the normalized difference built-up and soil index (NDBSI) represents the "dryness" of the landscape. In this study, a remote sensing ecological index (RSEI) evaluation model coupled with the above indices was used to monitor and evaluate the environmental quality (EQ) of a land reclamation project area. Humidity, greenness, heat, and dryness were represented by a humidity component, a normalized vegetation index, surface temperature, and dryness index, respectively; these indicators reflect changes in EQ. An RSEI is not suitable for classifying large areas of water. If a large area of water exists in a research area, it is better to mask the area before applying an RSEI; a water area is the region with the best environment by default. Since the construction of an RSEI requires a thermal infrared image, RSEI is mainly suitable for mesoscale mapping. The specific calculation method is shown in Table 2. 
Table 2. Details of the evaluation indicator system of sustainable development.

\begin{tabular}{|c|c|c|c|c|c|}
\hline Items & Index & Quantitative Method & Units & Indicator Definition & References \\
\hline \multirow{4}{*}{ Environmental } & Humidity $\left(x_{1}\right)$ & $\begin{array}{c}\text { Wet }(\mathrm{TM})=0.1151 \rho_{\text {Blue }}+0.1792 \rho_{\text {Green }}+0.3283 \rho_{\text {Red }}+ \\
0.3407 \rho_{\text {NIR }}-0.7117 \rho_{\text {SWIR1 }}-0.4559 \rho_{\text {SWIR2 }}\end{array}$ & $\%$ & Reflecting the humidity of surface water, soil, and vegetation & {$[37,38]$} \\
\hline & Greenness $\left(x_{2}\right)$ & $\mathrm{NDVI}=\left(\rho_{\mathrm{NIR}}-\rho_{\mathrm{Red}}\right) /\left(\rho_{\mathrm{NIR}}+\rho_{\mathrm{Red}}\right)$ & $\%$ & $\begin{array}{l}\text { Reflecting the parameters of plant biomass, leaf area index, } \\
\text { and vegetation coverage }\end{array}$ & {$[39,40]$} \\
\hline & Heat $\left(x_{3}\right)$ & $\begin{array}{c}L_{10}=\tau_{10}\left[\varepsilon_{10} B_{10}\left(T_{S}\right)+\left(1-\varepsilon_{10}\right) / I_{10} \downarrow\right]+I_{10} \uparrow \\
B_{10}\left(T_{s}\right)=\left[L_{10}-I_{10} \uparrow-\tau_{10}\left(1-\varepsilon_{10}\right) I_{10} \downarrow\right] / \tau_{10} \varepsilon_{10} \\
L S T=T_{b} /[1+(\lambda T / \phi) \ln \varepsilon] \cdot L S T=K_{2} / \ln \left(\left(K_{1} / B_{10}\right)\left(T_{S}\right)+1\right)\end{array}$ & ${ }^{\circ} \mathrm{C}$ & $\begin{array}{l}\text { Reflecting growth and distribution of vegetation, crop yield, } \\
\text { and evaporation of surface water resources }\end{array}$ & {$[33,41]$} \\
\hline & Dryness $\left(x_{4}\right)$ &  & $\%$ & $\begin{array}{l}\text { Reflecting land degradation synthesized by the index-based } \\
\text { built-up index and the bare soil index }\end{array}$ & [42-44] \\
\hline \multirow{4}{*}{ Food security } & Cropping $\left(x_{5}\right)$ & Crop sown area/cultivated area & time & Reflecting the intensive utilization level of cultivated land & [44] \\
\hline & Grain output $\left(x_{6}\right)$ & Grain yield/cultivated area & $\mathrm{kg} / \mathrm{km}^{2}$ & Grain output per $\mathrm{km}^{2}$ & [44] \\
\hline & Farmland protection $\left(x_{7}\right)$ & Primary farmland preservation area/cultivated area & $\%$ & Proportion of primary farmland preservation area & [45] \\
\hline & Agriculture expenditure $\left(x_{8}\right)$ & $\begin{array}{l}\text { Expenditure on agriculture, forestry, and water } \\
\text { conservation/fiscal expenditure }\end{array}$ & $\%$ & $\begin{array}{l}\text { Proportion of expenditure on agriculture, forestry, } \\
\text { and water conservancy }\end{array}$ & {$[46,47]$} \\
\hline \multirow{6}{*}{ Socio-economic } & Industrial growth $\left(x_{9}\right)$ & $\begin{array}{l}\text { Average growth rate of added value of industrial enterprises } \\
\text { above designated size }\end{array}$ & $\%$ & Reflecting the status of industrial development & [48] \\
\hline & Income of farmers $\left(x_{10}\right)$ & Per capita net income of residents in urban and rural areas & yuan & Reflecting the average income of residents & [49] \\
\hline & Social security $\left(x_{11}\right)$ & Fiscal expenditures on social security and employment input & yuan & Reflecting social security guarantee & [50] \\
\hline & Health security $\left(x_{12}\right)$ & Fiscal expenditures on health investment & yuan & Reflecting health investment & [51] \\
\hline & Urban-rural community $\left(x_{13}\right)$ & $\begin{array}{l}\text { Fiscal expenditures on urban and rural } \\
\text { community development }\end{array}$ & yuan & Support of urban-rural community development & [52] \\
\hline & Population density $\left(x_{14}\right)$ & Household registered population/area of town & Capita $/ \mathrm{km}^{2}$ & Reflecting the level of regional people agglomeration & [53] \\
\hline
\end{tabular}

Notes: $\rho_{\text {Blue }}, \rho_{\text {Green }}, \rho_{\text {Red }}, \rho_{\text {NIR }}, \rho_{\text {SWIR1 }}$, and $\rho_{\text {SWIR2 }}$ respectively represent the reflectance of the blue, green, red, near-infrared (NIR), short wave infrared 1 (SWIR1), and short wave

infrared 2 bands corresponding to the thematic mapper (TM) and the operational land unit (OLI) images; gain and skewness are the gain and offset values of TM6 band, or 0.056 and 1.238, respectively; $K_{1}$ and $K_{2}$ are scaling coefficients, obtained by image metadata, $K_{1}=606.09 \mathrm{~W} /\left(\mathrm{m}^{2} \times \mathrm{sr} \times \mu \mathrm{m}\right), K_{2}=1282.71 \mathrm{~K}$; center wavelength $\lambda$ is $11.48 \mu \mathrm{m}, \alpha$ is $1.438 \times 10^{-2} \mathrm{mK} ; \varepsilon_{6}$ is the surface specific emissivity based on TM6; while using the landsat OLI data, $L_{10}$ is the radiance value at the sensor, obtained by radiometric calibration; $\tau_{10}$ is the transmittance of the atmosphere in the thermal infrared band; $\varepsilon_{10}$ is the surface specific emissivity; $T_{\mathrm{S}}$ is the surface temperature; $B_{10}\left(T_{\mathrm{S}}\right)$ is the same black body as $T_{\mathrm{S}}$ radiation brightness; $\mathrm{I}_{10} \uparrow$ and $\mathrm{I}_{10} \downarrow$ are the radiance of the atmosphere up and down, respectively; the surface specific emissivity of the water bodies is 0.995 ; the surface specific emissivity $\varepsilon_{6}$ and $\varepsilon_{10}$ were obtained by Sobrino's NDVI threshold method; $\tau_{10}, I_{10} \uparrow$, and $I_{10} \downarrow$ parameters, with reference to the mid-latitude summer standard atmospheric profile, were obtained by interpolating the atmospheric profile according to the central latitude and longitude of the image and imaging time set; 1 RMB (yuan) $\approx 0.150 \$$. 


\subsubsection{Food Security and Socio-Economic Subsystem Evaluation Index}

The indicators of regional FS and SE subsystems reflect different aspects; however, the selected indicators are representative, accessible, and comparable. Also, the indicators in line with characteristics of sustainable regional development refer to existing literature; the details are shown in Table 3.

Table 3. Dynamic deviation state and characteristics of "eco-socio-economic" coordination.

\begin{tabular}{|c|c|c|c|c|c|}
\hline \multirow[b]{2}{*}{ Quadrant } & \multirow[b]{2}{*}{ Angle Range } & \multicolumn{3}{|c|}{ Vector Dynamic Deviation State } & \multirow[b]{2}{*}{ Description } \\
\hline & & $\begin{array}{l}\text { Ecological } \\
\text { Subsystem }\end{array}$ & $\begin{array}{l}\text { Socio-Economic } \\
\text { Subsystem }\end{array}$ & $\begin{array}{c}\text { Food Security } \\
\text { Subsystem }\end{array}$ & \\
\hline I & {$[11 \pi / 6,0)[0, \pi / 6)$} & 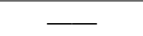 & - & + & \multirow{6}{*}{$\begin{array}{l}\text { "+" (or " }-") \text { indicate a positive (or negative) } \\
\text { vector that is higher (or lower) than the set } \\
\text { target; " }- \text { " indicates it could not be } \\
\text { determined if it meets the set target. }\end{array}$} \\
\hline II & {$[\pi / 6, \pi / 2)$} & + & - & - & \\
\hline III & {$[\pi / 2,5 \pi / 6)$} & + & - & - & \\
\hline IV & {$[5 \pi / 6,7 \pi / 6)$} & - & + & - & \\
\hline V & {$[7 \pi / 6,3 \pi / 2)$} & - & + & - & \\
\hline VI & {$[3 \pi / 2,11 \pi / 6)$} & - & - & + & \\
\hline
\end{tabular}

Multifunctional land use and economic development directly affect regional sustainability; the cropping system of the study region largely involves the intensive use of cultivated land. The grain output of cultivated land used for two to three crops annual will definitely be better than single cropped land or even land abandonment, so a multiple cropping index $\left(x_{5}\right)$ was used reflecting the intensive level of land use for cultivated land resources in the study area. Although a strong correlation exists between grain production and the normalized difference vegetation index (NDVI), regional grain output can still be calculated more accurately using statistics provided by townships; we used the grain output per unit of cultivated land $\left(x_{6}\right)$ to characterize the capacity of the study area for grain production. To ensure the sustainable development of agricultural production and the economy, China has passed legislation designed to implement special protection measures for prime farmland; the protection of prime farmland area $\left(x_{7}\right)$ is designed to guarantee regional food security. Finally, the guarantee of food security is inseparable from government input. The financial expenditures in regional agricultural production $\left(x_{8}\right)$, including agricultural, forestry, and water conservation expenditures, will comprehensively promote food output.

The social and economic development of townships and towns involve multiple sectors. During urbanization, the most important sectors include industrial development $\left(x_{9}\right)$, per capita income $\left(x_{10}\right)$, social security and employment $\left(x_{11}\right)$, health $\left(x_{12}\right)$, community development $\left(x_{13}\right)$, and others. At the same time, population density $\left(x_{14}\right)$ reflects the level of regional population agglomeration and is prominent when urbanization is ongoing. The level of industrialization in the town varies greatly due to natural endowments, policy support, and development opportunities; as a result, the growth rate of large-scale industries can better reflect the level of local economic growth and restructuring. The per capita income of residents can better reflect the comprehensive social and economic level of the region. These indicators are used to measure the achievements in social development and the protection of people's lives and work.

\subsection{Principal Component Analysis and Standardization of Indicators}

Principal component analysis (PCA) was used to integrate the indicators; the variance of the principal components was used as a weight to evaluate the various evaluation indicators. The specific steps started with Equation (1):

$$
I=P C A\left[f\left(x_{i}\right)\right]
$$

where $x_{\mathrm{i}}$ is the $i^{\text {th }}$ indicator, and $I$ also needs to be standardized. The value range normalized by the Equation (1) is [0,1]; the I closer is to 1, the better the sustainable development of the subsystem.

Because a large value in the first principal component represents good environmental conditions, the initial ecological index $I_{0}$ was obtained using Equation (2): 


$$
I_{0}=1-P C A_{1}\left[f\left(x_{i}\right)\right]
$$

where $P C_{1}$ is the first principal component.

Because the indicators that were obtained from remote sensing surveys, statistical yearbooks, and government websites were not uniform, the indicators were standardized based on the standard deviation, and the ranges were standardized to [0, 1], as shown in Equation (3).

$$
N I=\left(I-I_{\min }\right) /\left(I_{\max }-I_{\min }\right)
$$

where $N I$ is the normalized index value, $I$ is the numerical value of the index, and $I_{\max }$ and $I_{\min }$ are the maximum and minimum values of the indicator in the image, respectively.

\subsection{Multi-Dimensional Evaluation Model}

The evaluation of the coordination of regional environment changes and SE development, that is, the equilibrium state between various elements in a certain area, allowed the development of the following model: Assuming other conditions are homogeneous, the relationship between "eco-social-economic" is abstracted into a flute, the forces in the three directions in a Cartesian coordinate system. If all three forces reach the expected goal, the combined force is 0 , that is, $F$ is at the equilibrium point $\mathrm{O}$, and the regional elements achieve sustainable development; otherwise, if one or more of them do not reach or perhaps exceed the established goal, the force makes $F$ lean toward the equilibrium point. At this time, the regional development is in an unbalanced state. The concept is shown in Figure 3.



Figure 3. The quadrant of coordination skewness.

In the present study, $\mathrm{OA}, \mathrm{OB}$, and $\mathrm{OC}$ represent the positive development relationships of the ecological, SE, and FS subsystem, respectively. When the combined force is 0 , the angle between the corresponding angles of $\mathrm{OA}, \mathrm{OB}$, and $\mathrm{OC}$ is $2 \pi / 3$; when $\mathrm{F}$ deviates from the equilibrium point $\mathrm{O}, F$, the magnitude and orientation classes quantitatively characterize the corresponding deviation relationships. In order to facilitate the calculations, polar coordinates $(F, \theta)$ are used to characterize the sustainable regional development ordination. The polar diameter F represents the distance of any deviation. The larger the value of $\mathrm{F}$, the poorer the coordination of the research unit; the polar angle $\theta$ represents the direction of the deviation. The direction angles of $\mathrm{OA}, \mathrm{OB}$, and $\mathrm{OC}$ were defined as $\pi / 2$, $7 \pi / 6$, and $11 \pi / 6$, and the specific calculations for each variable are shown in Equations (4)-(6):

$$
O A=\frac{X_{1 i}-X_{1 S}}{X_{1 S}}
$$




$$
\begin{aligned}
& O B=\frac{X_{2 i}-X_{2 S}}{X_{2 S}} \\
& O C=\frac{X_{3 i}-X_{3 S}}{X_{3 S}}
\end{aligned}
$$

where $O A$ is the ecological degree of sustainability, $X_{1 i}$ is the ecological efficiency of the research unit, $X_{1 S}$ is the standard value of ecological efficiency, $O B$ is the SE degree of sustainability, $X_{2 i}$ is the SE efficiency of the research unit, $X_{2 S}$ is the standard value of SE efficiency, $O C$ is the FS degree of sustainability, $X_{3 i}$ is the FS efficiency of the research unit, and $X_{3 S}$ is the standard value of FS efficiency. All the standard values are the averages of the indicators.

Based on the rules of vector operation, the polar coordinates (F) were obtained according to Equations (7)-(9):

$$
\begin{aligned}
& \left\{\begin{array}{c}
\overrightarrow{\mathrm{OA}}=\left(x_{A}, y_{A}\right)=(0, O A) \\
\overrightarrow{\mathrm{OB}}=\left(x_{B}, y_{B}\right)=\left(\cos \left(\frac{1-\frac{\mathrm{O} B}{\mathrm{OB}}}{2} \pi-\frac{5 \pi}{6}\right)|O B|, \sin \left(\frac{1-\frac{|\mathrm{OB}|}{\mathrm{OB}}}{2} \pi-\frac{5 \pi}{6}\right)|O B|\right) \\
\overrightarrow{\mathrm{OC}}=\left(x_{C}, y_{C}\right)=\left(\cos \left(\frac{1-\frac{\mathrm{OCC}}{O C}}{2} \pi-\frac{5 \pi}{6}\right)|O C|, \sin \left(\frac{1-\frac{\mid O C}{O C}}{2} \pi-\frac{5 \pi}{6}\right)|O C|\right) \\
F_{1}^{\prime}=\left(x^{\prime}, y^{\prime}\right)=\overrightarrow{\mathrm{OA}}+\overrightarrow{\mathrm{OB}}+\overrightarrow{\mathrm{OC}}=\left(x_{A}+x_{B}+x_{C}, y_{A}+y_{B}+y_{C}\right)
\end{array}\right. \\
& F^{\prime}=\sqrt{x^{\prime 2}+y^{\prime 2}} \\
& \left\{\begin{array}{c}
\theta=\arctan \left(\frac{y^{\prime}}{x^{\prime}}\right) \quad x^{\prime} \geq 0, y^{\prime} \geq 0 \\
\theta=\arctan \left(\frac{y^{\prime}}{x^{\prime}}\right)+\pi \quad x^{\prime}<0 \\
\theta=\arctan \left(\frac{y^{\prime}}{x^{\prime}}\right)+2 \pi \quad x^{\prime} \geq 0, y^{\prime}<0
\end{array}\right.
\end{aligned}
$$

where $\overrightarrow{\mathrm{OA}}, \overrightarrow{\mathrm{OB}}, \overrightarrow{\mathrm{OC}}$ and $\overrightarrow{\mathrm{F}}$ are the vector expressions of ecological, economic, and social sustainability and the combined force of the three; $\mathrm{OA}, \mathrm{OB}$, and $\mathrm{OC}$ are the magnitudes of the forces where a positive or negative value indicates that its action direction is the same or opposite as the predetermined direction, respectively; $x_{\mathrm{A}}, x_{\mathrm{B}}, x_{\mathrm{C}}$ and $y_{\mathrm{A}}, y_{\mathrm{B}}, y_{\mathrm{C}}$ are the $\mathrm{x}$-axis and $\mathrm{y}$-axis coordinates. Based on the direction of the force determined in Figure 1 , the resultant coordinate $\left(x^{\prime}, y^{\prime}\right)$ was accumulated, and then the polar coordinate $\left(F^{\prime}, \theta\right)$ could be obtained. The extension lines $\mathrm{OA}^{\prime}, \mathrm{OB}^{\prime}$, and $\mathrm{OC}^{\prime}$ were made in the opposite direction of $\mathrm{OA}, \mathrm{OB}$ and $\mathrm{OC}$. As the direction of the ecological, economic, and social reverse development vectors, the results were divided into six quadrants, and the characteristics of the dynamic state of each quadrant vector were formed according to the positive and negative relationship of the three elements of the "eco-socio-economic" vector. Each quadrant had positive and negative vectors used to define the spatial position relationship of each research unit. Through the quadrant of the result and its relatives to the vector direction, the degree of coordination and matching between the elements of each research unit could be determined. For more details, see Table 3.

\section{Results}

\subsection{Spatial Differential Results for RSEI}

The RSEI was calculated using PCA in ArcGIS software before evaluating coordination; the indices of humidity, greenness, dryness, and heat were synthesized by band in each period after the standardization of the indices. Based on the spatial difference of the four indicators, RSEI fluctuated in different periods and different regions. In this study, the four indicators in each image were calculated separately, and then the average values were calculated. Finally, the index images in the two images were mosaicked together, and finally PCA was used. According to the calculation results of PCA, the contribution rate of the first principal component (FPC) of RSEI in 2018 was $84.29 \%$, indicating that the FPC contained most of the variation in the characteristics of the four indicators. In the FPC, WET (abbreviation for humidity), and NDVI had positive values, indicating that they had a promoting 
effect on the quality of the environment, while LST and NDBSI had negative values, indicating that the impact of these two indicators on the environment was negative.

In addition, the coefficient affected by LST was the largest one. During the process of the data, to calculate the result corresponding to the quality of the environment, the first PC grid value of the region was used in Equation (1) and then standardized to obtain the RSEI index. The standardized RSEI and the four indicator values are shown in Figure $4 a, b$, respectively.



(a)

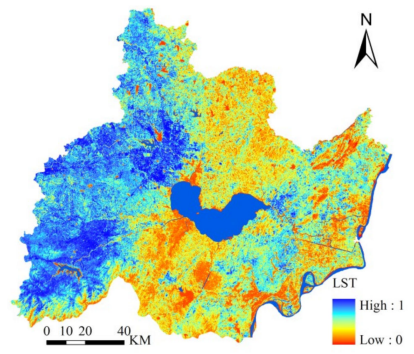

(c)

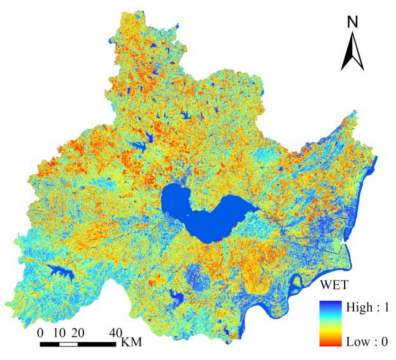

(b)

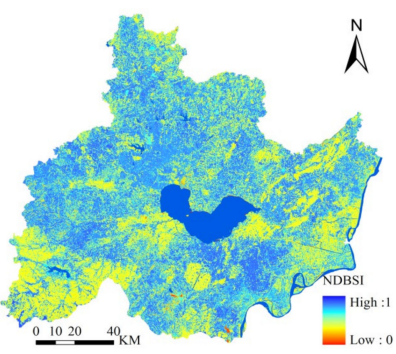

(d)

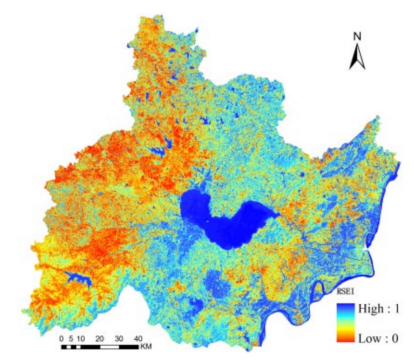

(e)

Figure 4. The Humidity (WET), normalized difference vegetation index (NDVI), land surface temperature (LST), normalized difference built-up and soil index (NDBSI), and remote sensing ecological index (RSEI) of Chaohu Lake Basin in 2018. (a) Greenness of Chaohu Lake Basin in 2018; (b) Humidity of Chaohu Lake Basin in 2018; (c) Heat of Chaohu Lake Basin in 2018; (d) Dryness of Chaohu Lake Basin in 2018; (e) The RSEI of Chaohu Lake Basin in 2018.

The region with an RSEI exceeding 0.5 only accounted for $25.40 \%$ of the total area. If the regional RSEI is classified on a scale using units of 0.2 from 0 to 1 , the total area of towns in which $I \in[0.4,0.6]$ accounted for $44.47 \%$ of all towns, while the area of towns which accounted $I \in[0.2,0.4],[0.6,0.8]$, and $[0.8,1.0]$ accounted for $37.27 \%, 5.59 \%$, and $3.95 \%$ of all towns, respectively. The overall EQ of the Chaohu Lake Basin in 2018 was slightly lower. Based on a digital elevation model of the Chao Lake Basin (Figure 5) and land use/cover types, the basin was divided into five regions (excluding the lake) to analyze the regional spatial changes in EQ. These regions included the Dabie Mountains in the southwest, the northwestern Hefei urban area, the northwestern hills, the farmland in the northeast, and the alluvial plain in the south. The findings suggest that the regional EQ has been greatly affected differences in precipitation and temperature. The highly erodible soil in the Dabie Mountains resulted in an ecological security pattern is characterized by being low in the north and high in the south; the southern area is one of the areas with a poor EQ in Chaohu Lake Basin. 




Figure 5. The DEM of Chaohu Lake Basin.

\subsection{Coordination of Sustainable Development}

When we considered the coordination of the eco-socio-economic system of the Chaohu Lake Basin, the county scale was too large and the region was too heterogeneous for this type of analysis. Therefore, we chose township scale and urban built-up areas such as downtown Hefei as research units and used PCA to evaluate the sustainable development of FS and SE subsystems. The three dimensions of each system were calculated using Equations (4)-(6), and the results are shown in Figure 6a-c. 




(a)

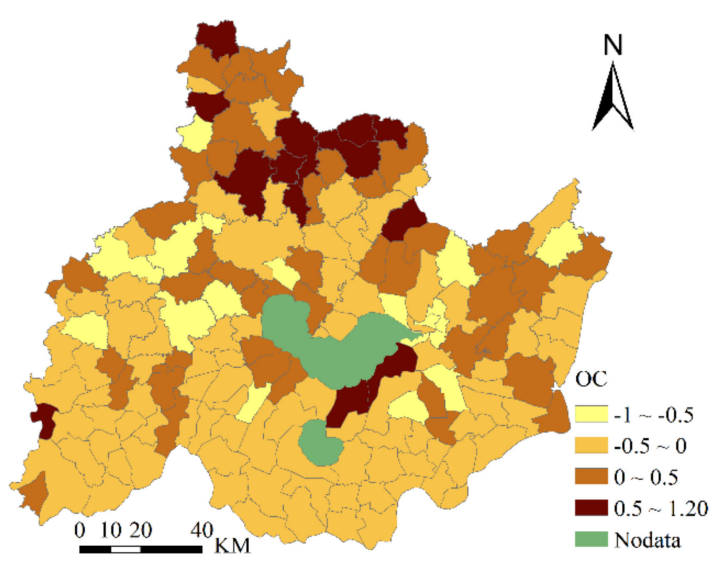

(c)

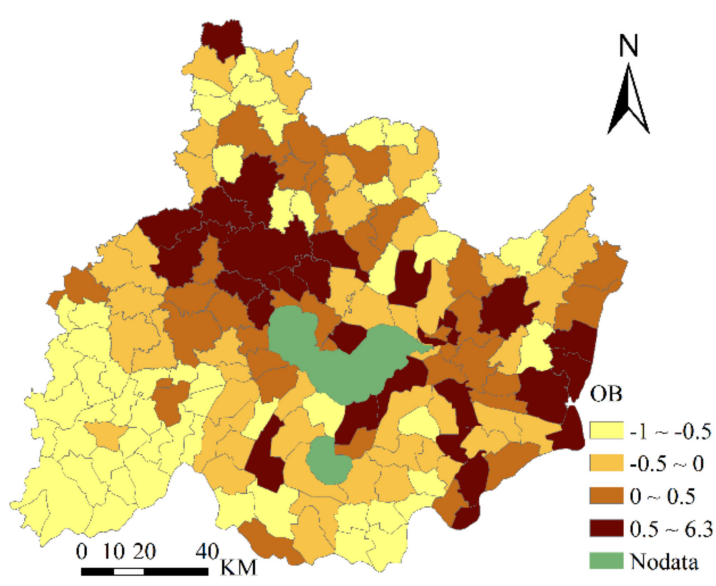

(b)

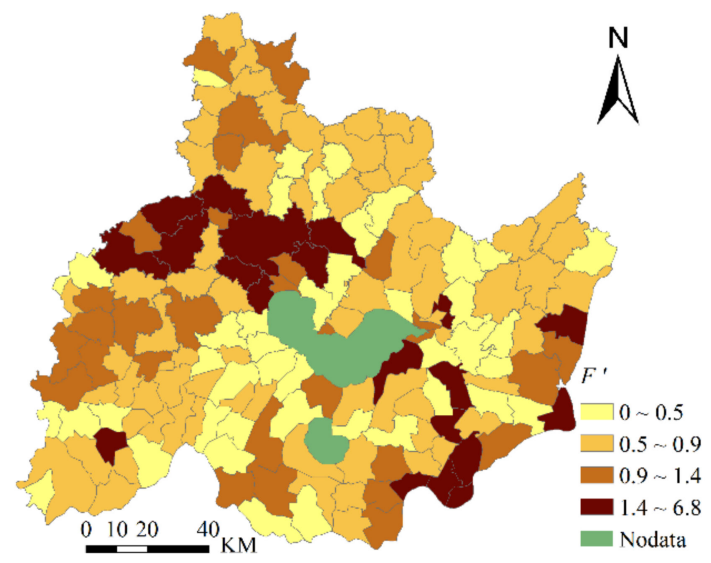

(d)

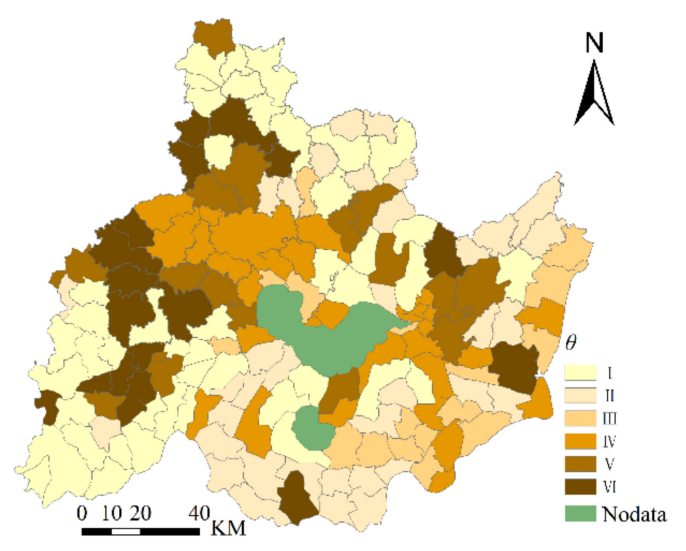

(e)

Figure 6. (a) Degree of ecological sustainability; (b) Degree of socio-economic sustainability; (c) Degree of food security sustainability; (d) Spatial differences in coordination; (e) Coordinated skewness.

4.2.1. Analysis of the State of Sustainable Development in Independent Systems

(1) Degree of ecological sustainability 
In 2018, the areas with an average degree of ecological degree of sustainability where $O A>0$ were mainly in the east of the Chaohu Lake Basin, which specifically includes towns with large areas of water or paddy fields. A total of 80 towns accounted for $57.36 \%$ of the entire basin (Figure $6 a$ ), of which the most prominent areas lie in the east along the Yangtze River; meanwhile, the EQ of 23 towns around the Dabie Mountains and Hefei City was lower than the average value. Judging only from the characteristics of the image, the environment in the northwest is negatively affected by the radiation of urban expansion.

\section{(2) Degree of SE sustainability}

During the study period, the areas with a high $\mathrm{OB}(O B>0)$ with the potential for sustainable socio-economic development were concentrated in downtown Hefei and in the counties of Chaohu, Hanshan, and Wuwei (including 61 towns; see Figure 6b). The sustainability of SE development in these well-developed regions was significantly higher than in other regions and was mainly dependent on the rapid development of their industries and large-scale service industries; this high OB is also inseparable from the government's support for these regions. The overall rate of sustainable socio-economic development of Jin'an District and Shucheng County in Lu'an City and the southern part of Lujiang County was low $(O B<-0.5)$, in which 54 towns are involved. The SE development in these regions was relatively slow and therefore was less sustainable.

\section{Degree of FS sustainability}

During the study period, the area of sustainable FS development $(O C>0)$ was mainly distributed in the northeast and southwest away from the city center where the terrain was relatively flat (Figure 6c). This area includes a total of 85 towns and accounts for $71.95 \%$ of the entire basin area. The Chaohu Lake Basin, a traditional agricultural production area, can still play a major role in the country's food security. However, 22 townships that are distributed in the downtown areas of Hefei and Chaohu as well as in Wuwei County still have the lowest sustainability of food security $(O C<-0.5)$. Overall, FS sustainability is approximately sufficient for regional development.

\subsubsection{Multidimensional System Coordination Analysis}

\section{(1) Coordination characteristics}

According to the geometric interval classification method, the value of $F^{\prime}$ can be divided into four categories, which are in a coordinated state $\left(0 \leq F^{\prime}<0.5\right)$, semi-coordinated state $\left(0.5 \leq F^{\prime}<1.0\right)$, antagonistic state $\left(1.0 \leq F^{\prime}<1.5\right)$, and disordered state $\left(F^{\prime}>1.5\right)$. According to the calculations, the average $F^{\prime}$ value was 0.887 , with no difference in most of each subsystem. It can be seen that the degree of coordination in support of sustainable development of the ecological, social, and economic systems of the Chaohu Lake Basin in 2018 was in a semi-coordinated state, and the environment, SE, and FS subsystems were still in the process of rapid development, meaning resource allocation needs to be further optimized.

\section{(2) Spatial differences in coordination}

In Figure $6 \mathrm{~d}$, in terms of the spatial pattern of coordination, 42 towns were in a coordinated state, accounting for $23.95 \%$ of the total basin area; these towns were decentralized and were mainly located in Lujiang, Hanshan, and Feidong counties, and the coordination degree of sustainable development in these areas were at the highest level; ecological protection, SE development, and guaranteed balanced FS development and mutual promotion, and the comprehensive matching effect of regional resources was the best here.

A total of 69 towns were in the semi-coordinated state, accounting for $42.43 \%$ of the basin area. They are mostly distributed around the coordination region and are widely distributed and without obvious clusters; this type of area also needs to be integrated in the use of resources. Although it is 
inferior to the coordination type, this type of an area can achieve positive resource investment effects through the integration of resource elements.

Thirty towns were in the antagonistic state, accounting for $19.65 \%$ of the entire basin. These towns are evenly distributed in the borders of the counties with the exception of Jin'an District and Changfeng County, which are also close to the imbalanced area. Compared with the semi-coordinated type, the degree of coordination of factor allocation in this region is skewed, and ecological, SE, and FS have been over- or under-developed in one aspect or another, which leads to the mutual resistance of the factors and affects the sustainable development of the area. If the effective deployment of resources is not carried out appropriately, this will gradually transition to an imbalanced state.

Twenty towns were in a state of imbalance, accounting for $13.97 \%$ of the total area, which was the smallest for the research units of the present study; these areas were concentrated in downtowns, county centers, and in some towns along the river or reservoirs. In terms of sustainable development coordination, the resources have not been effectively matched, and most of this imbalanced region has experienced rapid social and economic development, while the sustainability of the EQ and FS are relatively low. Under the comprehensive effects, this is a current problem area for eco-social-economic comprehensive planning and sustainable development of Chaohu Lake Basin and should be the object of an urgently needed adjustment of resources.

\section{(3) Skewness characteristics of sustainable development}

Identifying the coordinated skewness characteristics of each subsystem is helpful to finding problem areas and providing an effectively remedy. Coordination skewness $\theta$ was distributed in quadrants I-VI, with the area of each quadrant accounting for $30.58 \%, 19.94 \%, 8.65 \%, 15.73 \%, 12.20 \%$, and $12.91 \%$ of the basin, respectively. In general, there are the most dysfunctional quadrants (I, VI), followed by the transitional quadrants (II, V), and the least coordinated quadrants (III, IV). To some extent, this indicates that the development of the study area had an imbalance phenomenon in 2018, and resource allocation needs to be optimized.

Under the spatial pattern of sustainable regional development (Figure 6e), the resource allocation skewness of the dysfunctional quadrants is relatively serious, which reflects that only food safety is guaranteed, but environment security and SE development are lower than the currently established goals, which restricts the comprehensive and sustainable development of the region. Quadrant I mostly includes the traditional agricultural production areas of the Chaohu Lake Basin, such as Shucheng, Jin'an, and Changfeng that are mainly in the northernmost and southwest of the Chaohu Lake Basin. The coordination skewness of Quadrant I is expressed by having a better than average food supply and poor socioeconomic conditions; meanwhile, FS was high according to the set goals in Quadrant VI, although the environment of such areas was relatively poor. Such areas are mostly located in ecologically vulnerable areas located in hilly areas. These areas should be appropriately addressed to develop short-board subsystems in the future under the premise of protecting the environment.

The skewness of the degree of sustainable development coordination of the transitional quadrant stems from the inconsistency between the regional environment and SE development; that is, compared with the sustainable development goals in Quadrant II, the environment subsystem is more efficient and the matching SE development is extremely low; meanwhile, the coordination characteristics of the subsystems in Quadrant V are just the opposite. Quadrant II is widely distributed in the southern edge of the Chaohu Lake Basin and some towns in the northeast; Quadrant V is mainly located in Wuwei County or scattered around the cities. Ecological protection in these areas does not fully match the pace of rapid economic development.

The characteristics of the resource allocation and coordination skewness of the coordination quadrant are manifested because FS cannot be guaranteed, environmental protection or SE development has reached the currently established goals, and deviations in resource allocation are small. This quadrant is located in the center of some cities and counties, as well as in some strong industrial 
counties. It is represented by the urban areas of Hefei and Chaohu. In the future, the entire Chaohu Lake Basin should be developed radiantly with this region as the center.

\section{Discussion}

\subsection{Identification of Regional Sustainable Development Issues}

Identifying problem areas is a prerequisite for formulating and improving related regional related. Based on comprehensive, coordinated measures and their spatial characteristics, identifying problem areas that need to be optimized in support of the sustainable development of the Chaohu Lake Basin will help to formulate site-specific regional control measures for planned development. This starts with the idea that the requirements of sustainable development include maintaining, rationally using, and improving the natural resource base, which supports ecological resistance to stress as well as SE growth. As far as regional coordination is concerned, through an analysis of the spatial pattern of the research results, six types of problem areas were identified in the research unit of the study area:

\section{(1) Imbalanced between high agriculture yield and inefficient SE (Quadrant I)}

The area of Quadrant I is mainly distributed in 45 towns in the main agricultural production areas, and this area has the largest number of towns of all types. The average value of $F^{\prime}$ in this area is 0.67 , which is generally characterized by a high FS factor and slow SE development. This pattern is closely related to regional characteristics. As a major food producing area, the area has high land use rate and limited space for land use structure optimization. To coordinate sustainable regional development, it will be necessary to increase government investment in fixed assets, focus on SE development, and promote agriculture in the premise of ensuring future ecological and FS based on the development of agricultural auxiliary industries designed to boost the regional SE development.

(2) Imbalanced between inefficient SE and high ecological security (Quadrant II)

The region of Quadrant II is relatively scattered, involving 36 towns, with an average $F^{\prime}$ of 0.69 . In the Chaohu Lake Basin, except for the administrative area of Hefei City, although these SE areas are generally underdeveloped, they have a valuable and good EQ, so this pattern of inconsistency occurs. From the perspective of the overall sustainable development of the region, the region can still maintain a high-quality environment in the future. In view of the inefficient SE development, the income of residents in the region can be increased through government transfer payments and ecological compensation, and thereby better maintain a desired EQ.

(3) Imbalance between high ecological safety and low agricultural production (Quadrant III)

Regardless of SE conditions of the region, the region of Quadrant III has a better environment and a lower FS includes a total of 17 towns with an average $F^{\prime}$ of 0.77 . Except for Jin'an, Changfeng, and Feixi, a few towns in each county fall into this category. Because of a scarcity of cultivated land or the neglect of FS, this area lacks agriculture production. It is necessary to pay attention to FS in this region and to improve the land use rate and the efficiency of cultivated land use to maximize the food guarantee rate in the region in the next period. This will help the region to adapt to natural disasters and promote sustainable regional development. However, land use efficiency needs to be improved based on the premise of not harming the environment.

(4) Imbalance between low agriculture production and high SE efficiency (Quadrant IV)

The low level of agricultural production, rapid SE development, and the EQ is not too bad in the area of Quadrant IV, which mainly includes the city or county centers for a total of 28 towns with an average $F^{\prime}$ of 1.87. The current level of urban and related industrial development in such areas means that almost no more cultivated land is available for reclamation, so it is not practical to increase 
agricultural output in these areas. A food reserve system needs to be established and food needs to be transferred from other regions to adjust the balance of grain supply and demand across the county and to guarantee FS. If natural disasters occur in the county, the ability to transfer food from the outside will also be required. Meanwhile, part of the financial support for the region should be used to finance ecological compensation funds to compensate local residents for ecological conservation in other regions.

\section{(5) Imbalance between high SE efficiency and low ecological security (Quadrant V)}

The area of Quadrant V is characterized by economic development that has occurred at the expense of the environment; most of these areas are well-known industrial towns. The 17 towns have an average $F^{\prime}$ of 0.62 , which shows that the degree of coordination of sustainable development in such regions is mostly in a semi-coordinated state. Then future sustainable regional development can be coordinated by optimizing resource allocation. Sustainable development will require strengthening the environment, which means putting ecological protection first, and focusing on developing green and pollution-free enterprises.

(6) Imbalance between low ecological security and high agriculture production (Quadrant VI)

The area in Quadrant VI includes 18 towns with an average $F^{\prime}$ of 0.76 . This area has good regional coordination and is also the main agricultural production area in the Chaohu Lake Basin. However, the environment is poor because of geomorphological undulations and a high potential for soil erosion. Management should focus on controlling soil erosion and identifying fragile areas to prevent ecological and anthropogenic damage in the future to maintain efficient crop production. This area is suitable for inclusion in a restoration plan to protect the cultivated land; after the fertility of cultivated land is restored, food security would be guaranteed.

\subsection{Multifunctional Zoning in Support of Regional Sustainable Development}

The county area is the most important and basic space unit in the administrative management system used for land in China. The county unit reflects the system's own integrity, stability, and regional multi-functionality. Current China's spatial planning of land use at the provincial-city-county-level had been implemented with the goal of forming "a county, a plan, and a blueprint." In this paper, zones divided based on land space planning functions divide the study area into priority development, agglomeration development, agricultural development, ecological conservation, and prohibited development zones (Figure 7). Based on regional industrial strengths, the development of SE systems is prioritized in the priority development and agglomeration development zones. The main function of the comprehensive agricultural development zone is to realize the sustainable development of regional agriculture and ensure FS; development is restricted in this zone. The ecological conservation zone refers to areas where ecological functions are important or ecosystems are fragile, and basic conditions for ecological and economic development are good. Prohibited development zones include the key ecological function areas and resource areas requiring special protection.

Because regional development is multi-functional, regional linkages and compound functions should be considered during sustainability analysis. A comprehensive evaluation system used to analyze the multifunctional suitability of land use and its functional zoning should meet the requirements of a land spatial planning system. Based on the diagnosis of regional problems, social, ecological, and economic development should be integrated to support the three subsystems of SE, FS, and ES, to allow the integrated and sustainable development of a system run in an orderly way. 




Figure 7. Major function regionalization.

\section{Conclusions}

This paper analyzes the core indicators of the three subsystems including ecological security, SE development, and food security. First, the regional EQ was calculated so that an eco-socio-economic model could be constructed based on a mechanical equilibrium model. The study used a multidimensional evaluation model and takes the township as the research unit in 2018. Then, the coordination degree of ecological security, SE development, and food security in the Chaohu Lake Basin was comprehensively evaluated. The main conclusions are as follows:

(1) The environment of the Chaohu Lake Basin is mainly affected by factors such as climate, urbanization, and topography. The EQ of the entire study area is slightly inferior to that of other areas, and a slight trend toward deterioration was identified. The spatial differences across the landscape are obvious. The urban centers radiate into the surrounding areas so that the environment in those area tends to be degraded, while the environment in other areas is expected to improve over time in the future. Ecological conservation should continue to be emphasized in the future in support of sustainable regional development.

(2) The coordination of ecological security, SE development, and food security in the Chaohu Lake Basin is generally in the process of development and run-in, especially in towns and city surrounding areas. However, many towns are still in a coordinated state, meaning sustainable and coordinated development can still be achieved on a regional scale through resource optimization. The area was divided into six patterns according to the degree of coordination deviation. Most of the areas are mainly rich in grain production but poor in economic development conditions. It can be seen that the overall SE conditions in the Chaohu Lake Basin need to be improved while ensuring that the environment is not degraded.

(3) Based on the requirements of the main functional zoning of a county's territorial and spatial planning, the 161 towns in the entire Chaohu Lake Basin were divided into five functional zones, of which most are considered to be comprehensive agricultural zones; after all, the basin is a traditional agricultural area. The second most common zones are ecological conservation areas in which development is restricted; these areas have good environmental conditions. These regions continue to be maintained, although the protection of ecologically fragile areas needs to be strengthened. In the future, ecological compensation and food security system development should be carried out in urban priority and agglomeration development areas to pave the way for sustainable regional development.

This study provides monitoring of important nature ecosystems and serves as a guide to future sustainable regional development by providing directions and paths to follow, it can be used as a basis for spatial planning and also as a reference for eco-functional zoning that is applicable to various 
natural regions worldwide. In the future, this research will continue to expand to explore 30-years of change using historical data so as to better study sustainable development.

Author Contributions: All of the authors contributed to this research. B.G., X.J., and Y.Z. conceived the study and were responsible for the design and development of the data analysis. B.G. and Y.F. were responsible for data collection and analysis. X.J. and Y.F. were responsible for data interpretation. B.G. wrote the first draft of the article. All authors have read and agreed to the published version of the manuscript.

Funding: This research was funded by National Natural Science Foundation of China, grant number 41701107; Research Foundation of Anhui University, grant number Y040418330.

Conflicts of Interest: The authors declare no conflict of interest.

\section{References}

1. Huang, H.; Li, Q.; Zhang, Y. Urban Residential Land Suitability Analysis Combining Remote Sensing and Social Sensing Data: A Case Study in Beijing, China. Sustainability 2019, 11, 2255. [CrossRef]

2. Li, Y.; Fan, P.; Liu, Y. What makes better village development in traditional agricultural areas of China? Evidence from long-term observation of typical villages. Habitat. Int. 2019, 83, 111-124. [CrossRef]

3. Liu, Y.; Li, J.; Yang, Y. Strategic adjustment of land use policy under the economic transformation. Land Use Policy 2018, 74, 5-14. [CrossRef]

4. Wenner, F. Sustainable urban development and land value taxation: The case of Estonia. Land Use Policy 2018, 77, 790-800. [CrossRef]

5. Long, H.; Zou, J.; Pykett, J.; Li, Y. Analysis of rural transformation development in China since the turn of the new millennium. Appl. Geogr. 2011, 31, 1105. [CrossRef]

6. Liu, Y.; Yang, Y.; Li, Y.; Li, J. Conversion from rural settlements and arable land under rapid urbanization in Beijing during 1985-2010. J. Rural. Stud. 2017, 51, 141-150. [CrossRef]

7. Xie, H.; Wang, P.; Yao, G. Exploring the Dynamic Mechanisms of Farmland Abandonment Based on a Spatially Explicit Economic Model for Environmental Sustainability: A Case Study in Jiangxi Province, China. Sustainability 2014, 6, 1260-1282. [CrossRef]

8. Long, H.; Liu, Y. Rural restructuring in China. J. Rural. Stud. 2016, 47, 387-391. [CrossRef]

9. Vukomanovic, J. Exurbia as Physical and Social Space: Landscape Drivers and Ecological Impacts of Amenity Migration in the New West; The University of Arizona: Tucson, AZ, USA, 2013.

10. Li, Y.; Cao, Z.; Long, H.; Liu, Y.; Li, W. Dynamic analysis of ecological environment combined with land cover and NDVI changes and implications for sustainable urban-rural development: The case of Mu Us Sandy Land, China. J. Clean. Prod. 2017, 142, 697-715. [CrossRef]

11. Barr, B.; Bambra, C.; Whitehead, M. The impact of NHS resource allocation policy on health inequalities in England 2001-11: Longitudinal ecological study. BMJ Clin. Res. 2014, 348, g3231. [CrossRef]

12. Kim, C.H. The Ecological Impact of the Korean Saemaul (New Rural Community) Movement, 1970-1979; Springer: Cham, Switzerland, 2015.

13. Reheman, A.; Rusuli, Y. Ecological effects of the First Water Diversion Hub Station in Kaidu River based on the vegetation index. Sci. Soil Water Conserv. 2017, 15, 115-124.

14. Shang, W.; Gong, Y.; Wang, Z.; Stewardson, M.J. Eco-compensation in China: Theory, practices and suggestions for the future. J. Environ. Manag. 2018, 210, 162-170. [CrossRef] [PubMed]

15. Khalil, E. Analysis of Determinants of Foreign Direct Investment in Egypt (1970-2013). Eur. Sci. J. 2015, 2, 329-361.

16. Guozhi, L.I.; Chen, G.; School, B. Research on Evolution Path and Influencing Factors of Ecological Compensation of Natural Resources. Environ. Sci. Technol. 2017, 40, $200-205$.

17. Berihun, M.L.; Tsunekawa, A.; Haregeweyn, N.; Meshesha, D.T.; Adgo, E.; Tsubo, M.; Masunaga, T.; Fenta, A.A.; Sultan, D.; Yibeltal, M. Exploring land use/land cover changes, drivers and their implications in contrasting agro-ecological environments of Ethiopia. Land Use Policy 2019, 87, 104052. [CrossRef]

18. Janker, J.; Mann, S.; Rist, S. Social sustainability in agriculture-A system-based framework. J. Rural Stud. 2019, 65, 32-42. [CrossRef]

19. Wei, T.; Hewings, G.J.D. Do city-county mergers in China promote local economic development? Econ. Transit. 2017, 25, 439-469. 
20. Gao, X.; Shen, J.; He, W.; Sun, F.; Zhang, Z.; Guo, W.; Zhang, X.; Kong, Y. An evolutionary game analysis of governments' decision-making behaviors and factors influencing watershed ecological compensation in China. J. Environ. Manag. 2019, 251, 109592. [CrossRef]

21. Adams, H.; Adger, W.N.; Ahmad, S.; Ahmed, A.; Streatfield, P.K. Multi-dimensional well-being associated with economic dependence on ecosystem services in deltaic social-ecological systems of Bangladesh. Reg. Environ. Chang. 2020, 20,1-16. [CrossRef]

22. Yao, L.; Li, X.; Li, Q.; Wang, J. Temporal and Spatial Changes in Coupling and Coordinating Degree of New Urbanization and Ecological-Environmental Stress in China. Sustainability 2019, 11, 1171. [CrossRef]

23. Cheng, H.; Qiong, X.U.; Guo, Y.; University, H.N. Temporal and Spatial Evolution of the Coupling Coordinated Development between Tourism Resources Development and Ecological Environment in China. Econ. Geogr. 2019, 39, 230-240.

24. Marandure, T.; Dzama, K.; Bennett, J.; Makombe, G.; Mapiye, C. Theoretical and practical considerations in the development of a methodological framework for evaluating sustainability of low-input ruminant farming systems in developing countries. Environ. Sustain. Indic. 2020, 8, 100058. [CrossRef]

25. Kaswan, M.S.; Rathi, R. Green Lean Six Sigma for sustainable development: Integration and framework. Environ. Impact Asses. 2020, 83, 106396. [CrossRef]

26. Eustachio, J.H.P.P.; Caldana, A.C.F.; Liboni, L.B.; Martinelli, D.P. Systemic indicator of sustainable development: Proposal and application of a framework. J. Clean. Prod. 2019, 241, 118383. [CrossRef]

27. Nilsson, M.; Griggs, D.; Visbeck, M. Policy: Map the interactions between Sustainable Development Goals. Nature 2016, 534, 320-322. [CrossRef]

28. Barnes, M.L.; Bodin, O.; Mcclanahan, T.R.; Kittinger, J.N.; Hoey, A.S.; Gaoue, O.G.; Graham, N.A.J. Social-ecological alignment and ecological conditions in coral reefs. Nat. Commun. 2019, 10, 1-10. [CrossRef]

29. Fu, B.; Zhang, J.; Wang, S. Classification-coordination-collaboration: A systems approach for advancing Sustainable Development Goals. Natl. Sci. Rev. 2020, 7, 838-840. [CrossRef]

30. James, L. Toward a Remote Sensing Solution for Regional Sustainability Assessment and Monitoring. Sustainability 2014, 6, 2067-2086.

31. Xu, H.; Wang, M.; Shi, T.; Guan, H.; Fang, C.; Lin, Z. Prediction of ecological effects of potential population and impervious surface increases using a remote sensing based ecological index (RSEI). Ecol. Indic. 2018, 93, 730-740. [CrossRef]

32. $\mathrm{Hu}, \mathrm{X} . ; \mathrm{Xu}, \mathrm{H}$. A new remote sensing index for assessing the spatial heterogeneity in urban ecological quality: A case from Fuzhou City, China. Ecol. Indic. 2018, 89, 11-21. [CrossRef]

33. Wu, J.; Wang, X.; Zhong, B.; Yang, A.; Jue, K.; Wu, J.; Zhang, L.; Xu, W.; Wu, S.; Zhang, N.; et al. Ecological environment assessment for Greater Mekong Subregion based on Pressure-State-Response framework by remote sensing. Ecol. Indic. 2020, 117, 106521. [CrossRef]

34. Guo, B.; Fang, Y.; Jin, X.; Zhou, Y. Monitoring the effects of land consolidation on the ecological environmental quality based on remote sensing: A case study of Chaohu Lake Basin, China. Land Use Policy 2020, 95, 104569. [CrossRef]

35. Zhao, P.; Sun, J. The Impact and Enlightenment of Beijing Administrative Division Adjustment on Urban Development. Urban Insight 2011, 5, 107-117.

36. Rongdi, G.; Lixin, T.; Wenchao, L. Analysis of Influencing Factors on Energy Efficiency of Yangtze River Delta Urban Agglomeration Based on Spatial Heterogeneity. Energy Procedia 2019, 158, 3234-3239. [CrossRef]

37. Crist, E.P. A TM Tasseled Cap equivalent transformation for reflectance factor data. Remote Sens. Environ. 1985, 17, 301-306. [CrossRef]

38. Baig, M.H.A.; Zhang, L.; Shuai, T.; Tong, Q. Derivation of a tasselled cap transformation based on Landsat 8 at-satellite reflectance. Remote Sens. Lett. 2014, 5, 423-431. [CrossRef]

39. Hu, S.; Mo, X.; Lin, Z. Optimizing the photosynthetic parameter Vcmax by assimilating MODIS-fPAR and MODIS-NDVI with a process-based ecosystem model. Agric. Forest Meteorol. 2014, 198, 320-334. [CrossRef]

40. Weber, D.; Schaepman-Strub, G.; Ecker, K. Predicting habitat quality of protected dry grasslands using Landsat NDVI phenology. Ecol. Indic. 2018, 91, 447-460. [CrossRef]

41. Cassidy, L.; Southworth, J.; Gibbes, C.; Binford, M. Beyond classifications: Combining continuous and discrete approaches to better understand land-cover change within the lower Mekong River region. Appl. Geogr. 2013, 39, 26-45. [CrossRef] 
42. Jing, Y.; Zhang, F.; He, Y.; Kung, H.; Johnson, V.C.; Arikena, M. Assessment of spatial and temporal variation of ecological environment quality in Ebinur Lake Wetland National Nature Reserve, Xinjiang, China. Ecol. Indic. 2020, 110, 105874. [CrossRef]

43. Liu, Y.; Feng, Q.; Wang, C.; Tang, Z. A risk-based model for grassland management using MODIS data: The case of Gannan region, China. Land Use Policy 2018, 72, 461-469. [CrossRef]

44. Liu, J.; Jin, X.; Xu, W.; Fan, Y.; Ren, J.; Zhang, X.; Zhou, Y. Spatial coupling differentiation and development zoning trade-off of land space utilization efficiency in eastern China. Land Use Policy 2019, 85, 310-327. [CrossRef]

45. Yun, W.; Yu, Z. Ecological landscaping strategy of rural land consolidation in China. Trans. Chin. Soc. Agric. Eng. 2011, 27, 1-6.

46. Xu, Z.; Xu, J.; Deng, X.; Huang, J.; Uchida, E.; Rozelle, S. Grain for Green versus Grain: Conflict between Food Security and Conservation Set-Aside in China. World Dev. 2006, 34, 130-148. [CrossRef]

47. Van Meijl, H.; Shutes, L.; Valin, H.; Stehfest, E.; van Dijk, M.; Kuiper, M.; Tabeau, A.; van Zeist, W.; Hasegawa, T.; Havlik, P. Modelling alternative futures of global food security: Insights from FOODSECURE. Glob. Food Secur. 2020, 25, 100358. [CrossRef]

48. Shi, T.; Yang, S.; Zhang, W.; Zhou, Q. Coupling coordination degree measurement and spatiotemporal heterogeneity between economic development and ecological environment-Empirical evidence from tropical and subtropical regions of China. J. Clean. Prod. 2020, 244, 118739. [CrossRef]

49. Li, W.; Yi, P.; Zhang, D.; Zhou, Y. Assessment of coordinated development between social economy and ecological environment: Case study of resource-based cities in Northeastern China. Sustain. Cities Soc. 2020, 59, 102208. [CrossRef]

50. Fang, C.; Liu, H.; Li, G. International progress and evaluation on interactive coupling effects between urbanization and the eco-environment. J. Geogr. Sci. 2016, 26, 1081-1116. [CrossRef]

51. Boyacioğlu, E.Z. The importance of health expenditures on sustainable development. Int. J. Soc. Sci. Humanit. Stud. 2012, 4, 147-158.

52. Lu, C.; Bing, X.; Lu, C.; Wang, T.; Lu, J.; Zhang, Z.; Ren, W. Sustainability Investigation of Resource-Based Cities in Northeastern China. Sustainability 2016, 8, 1058. [CrossRef]

53. Long, H.; Tu, S.; Ge, D.; Li, T.; Liu, Y. The allocation and management of critical resources in rural China under restructuring: Problems and prospects. J. Rural Stud. 2016, 47, 392-412. [CrossRef]

Publisher's Note: MDPI stays neutral with regard to jurisdictional claims in published maps and institutional affiliations.

(C) 2020 by the authors. Licensee MDPI, Basel, Switzerland. This article is an open access article distributed under the terms and conditions of the Creative Commons Attribution (CC BY) license (http://creativecommons.org/licenses/by/4.0/). 